See discussions, stats, and author profiles for this publication at: https://www.researchgate.net/publication/323584484

\title{
The Roles of Socioeconomic Status, Occupational Health and Job Rank on the Epidemiology of Different Psychiatric Symptoms in a Sample of UK Workers
}

Article in Community Mental Health Journal · March 2018 DOI: 10.1007/s10597-018-0259-3

\section{CITATIONS}

5

3 authors:

Barbara Lopes

CINEICC

24 PUBLICATIONS 182 CITATIONS

SEE PROFILE

Rusi Jaspal

De Montfort University

106 PUBLICATIONS 1,394 CITATIONS

SEE PROFILE
READS

92

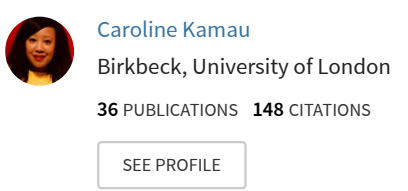

Some of the authors of this publication are also working on these related projects:

Public Health England View project

Understanding and improving the occupational health of medical doctors: A systematic review and meta-analysis of prevalence and a randomised controlled trial of an intervention View project 
The roles of socioeconomic status, occupational health and job rank on the epidemiology of different psychiatric symptoms in a sample of UK workers

\author{
B. Lopes ${ }^{1}$ \\ $\&$ \\ C. $\mathrm{Kamau}^{2}$ \\ $\&$ \\ R. Jaspal ${ }^{3}$
}

\footnotetext{
${ }^{1}$ CINEICC, Faculdade de Psicologia e de Ciências da Educação da Universidade de Coimbra

${ }^{2}$ Birkbeck, University of London, Department of Organisational Psychology

${ }^{3}$ De Montfort University, Faculty of Health and Life Sciences, Department of Psychology
}

Correspondence: Dr Barbara Lopes, CINEICC, Faculdade de Psicologia e de Ciências da Educação da Universidade de Coimbra, Rua do Colégio Novo, 3001-802, Coimbra, Portugal. Webpage: http://www.uc.pt/en/fpce/research/CINEICC. Email: bcslopes@protonmail.com

Acknowledgements: The authors acknowledge that the UK Office for National Statistics is the copyright holder of the psychiatric morbidity survey dataset and was not involved in its interpretation for this article. 


\begin{abstract}
There is a considerable gap in epidemiological literature about community mental health showing how psychiatric symptoms are associated with job rank, socioeconomic status, and occupational health. We examine data from 4,596 employees collected in the United Kingdom's Psychiatric Morbidity among Adults Living in Private Households Survey. There were 939 workers in managerial jobs, 739 in supervisory jobs and 2,918 employees in lower ranking jobs. Of the 4,596 workers, 2,463 had depressive symptoms and 2,133 no depressive symptoms. Job rank, household gross income, social class, personal gross income and socioeconomic group were significantly associated with general health, occupational health and depressive and avoidant symptoms. Job rank, occupational and physical health also explained the variance in paranoid and avoidant symptoms among the employees. This study shows that severe psychopathology is related to workers' job rank.
\end{abstract}

Key words: Occupational health; Epidemiology; Depression; Paranoia; Job Rank; Socioeconomic status; 


\section{Introduction}

Socioeconomic status can have an important impact on health and mortality (Adler, Boyce, Chesney, Cohen, Folkmann, Kahn and Syme, 1994; Feinstein, 1993; Marmot \& Smith, 1991; Winkleby, Jatulis, Frank and Fortmann, 1971). Socioeconomic status predicts a myriad of health problems, including the onset of autoimmune diseases (Calixto \& Anaya, 2014), cardiorespiratory fitness (Schmueli et al., 2014) and obesity (Costa-Font, HernandezQuevedo \& Jimenez-Rubio, 2014). Both objective and subjective socioeconomic indicators have been implicated (Demakakos, Nazroo, Breeze and Marmot, 2008). This is because variables such as occupational prestige, job type and working conditions co-vary with income in predicting health (Adler et al., 1994; Cottini, 2012; Fujishiro, Xu and Gong, 2010). High occupational status is associated with a better income, lifestyle and diet but also with less exposure to occupational hazards and job stress, which can have a long-term impact on mortality. The famous Whitehall I and II longitudinal prospective cohort study showed that mortality was higher among people who worked in low-ranking jobs (Marmot, Rose, Shipley \& Hamilton, 1978; Marmot \& Smith, 1991). The more senior an employee is within the job role hierarchy, the longer they can expect to live, whereas employees who work in lowranking jobs present progressively deteriorating health (Marmot et al., 1978; Marmot \& Smith, 1991). There is evidence that occupational status (job rank) relates to mental and physical health, and also evidence that socioeconomic status relates to mental and physical health. Individuals of low economic status are more likely to suffer from mental health issues, such as depression (Lorant, Eaton, Philippot \& Ansseau, 2003; Lorant, Crouz, Weich, Deliège, Mackenbach \& Ansseau, 2007), as well as a variety of physical health problems (Conway et al., 2008; Marmot, 2005). There is some research exploring the prevalence of 
psychiatric symptoms in specific professions (e.g. Medisauskaite and Kamau, 2017a) but there remains a gap in evidence about workers in different ranks. As a step toward understanding the antecedents of high mortality among low-ranking employees, we explore the contribution of job rank and socioeconomic status to poor physical and mental health.

\section{Occupational status and psychiatric symptoms}

From a psychological point of view, occupational status (that is, a worker's job rank) brings with it some real or imagined social threat. Therefore it is useful to explore the connection between job rank and mental/physical health. The danger of being exploited, criticized or ostracized constitutes a 'threat' situation. This can instigate a psychological defense and style of thinking that can veer into psychopathology, namely the presence of depressive, paranoid and avoidant symptoms (Gilbert, 1993; 2001). Low-ranking workers can develop fears about poor job security or promotional chances, as well as fearing difficulties from higher-ranking colleagues. Tenure in an organization affects feelings of selfconsciousness and susceptibility to paranoid cognitions, characterized by fears of malevolence from others and the belief that they will intentionally cause one harm (Freeman, Garety, Kuipers, Fowler \& Bebbington, 2002). This could explain the prevalence of psychopathological symptoms such as paranoia in organizations (Kramer, 1994; Freeman Freeman, Garety, Bebbington, Smith, Rollinson \& Fowler, 2005).

Hierarchical relationships are important and prevalent within organizations, suggesting that low job rank has the potential to increase the risk of psychiatric and physical symptoms. Among the hallmarks of workplace relationships are significant asymmetries in 
power, status, access to information, and evaluative scrutiny (Kramer, 1994). From the standpoint of workers with low job ranks, trust in those above them is critical to well-being because of their vulnerability and dependence for access to organizational resources such as promotion, pay increases, attractive assignments, desirable office space, staff support, and other resources needed to get work done. Workers with a low job rank may also depend on those above them for less tangible but no less important psychological resources, such as positive reinforcement, mentoring, social support, and empathy. Workers with lower job ranks can feel uncertainty about how they are regarded and where they stand (Kramer, 1994, 1999) as a result of which they could develop paranoid ideation because feeling scrutinized by their superiors increases self-referential biases, in turn leading to feelings of vulnerability and mistrust (Kramer, 1999).

Other research supports the idea that paranoia, anxiety and depressive symptoms are common among low-ranking employees (Gilbert, 1992; Lerner et al., 2004). They also appear to be at risk of avoidant traits because being submissive towards seniors with the power to do harm (e.g. making their working life difficult or having the power to get them fired) can make disengagement and avoidant thinking quite adaptive in the face of social threats (Gilbert, 2001). Behaviorally, low-ranking workers might cope by avoiding applying for promotions, competing with co-workers or promoting his/her self-advancement but research is needed to establish whether avoidant thinking is indeed more prevalent in this population. Moreover, because low job rank can mean less power to challenge others' wrongdoing within the workplace, this perceived inability to control one's occupational fate could lead low-rankers to a state of arrested flight (Gilbert, Boxall, Cheung \& Irons, 2005). Existing work suggests that this psychological state is associated with feelings of panic, 
paranoia and depression (Gilbert et al., 2005). There is also a high prevalence of anxious and depressive symptoms among people who feel entrapped and powerless to change their current status (Gilbert, Gilbert \& Irons, 2004). Such feelings of negative mood, sadness, hopelessness, worthlessness, guilt and worry form part of the diagnostic criteria for mood disorders (Rhode, Lewinsohn \& Seewley, 1991). We therefore explored whether there is a higher prevalence of depression (e.g., low mood and worry), avoidance (e.g., feelings of inadequacy, fear and avoidance of social and work activities and a preoccupation with rejection or criticism from others), paranoia (e.g. persecutory beliefs about being exploited, harmed or deceived; constant suspicions and a preoccupation with doubts about the loyalty or trustworthiness of others) and poorer occupational health among workers with low job ranks compared to managers and supervisors.

Socioeconomic status, occupational status and psychiatric symptoms

In the UK, socioeconomic status is understood using standard classification systems such as the National Statistics Socio-Economic Classification (NS-SEC; Goldthorpe 2007). The NS-SEC consists of employment categories ranging from higher managerial positions to long-term unemployment. We therefore explored the connection between a worker's socioeconomic classification and the prevalence of psychiatric symptoms. In addition, because socio-economic status co-varies with income (Winkleby et al., 1992), we explored the connection between workers' income and psychiatric symptoms.

There is considerable evidence that low socioeconomic status and income are associated with a higher prevalence of psychiatric symptoms but less is known about the prevalence of psychiatric symptoms among people in work. For example, depression is 
associated with low socioeconomic status and job loss or poor workplace productivity (Lorant et al., 2003; Simon et al., 2000; Zhang et al., 1999). A meta-analysis of 51 prevalence studies showed that low socioeconomic status slightly increases the risk of episode onset and moderately increases the risk of chronic depression (Lorant et al., 2003). Lorant et al. (2003) suggested that this is because a low socioeconomic status offers fewer personal resources with which to buffer the impact of stress on depression. A longitudinal study by Lorant et al. (2007) found that 1-year increases in material hardship (e.g., financial strain, deprivation and poverty) led to increased depression risk. We therefore explored the prevalence of depression and other psychiatric symptoms among workers, while also taking into consideration socioeconomic factors.

By exploring the prevalence of psychiatric symptoms among people in work, we hope to add to research showing the need for improved support for workers coping with psychiatric disorders (Kamau, 2016, 2017a). Indeed, there is research to suggest that employment outcomes improve after symptoms decrease (Lerner et al., 2004; Schoenbaum et al., 2001; Simon et al., 2000) in samples of low-ranking workers in which there is a high prevalence of depression and other psychiatric symptoms. This research can also inform interventions that improve workers' access to treatment for psychiatric disorders because high-quality depression treatment improves employment outcomes (Kroenke et al., 2001). By highlighting the prevalence of psychiatric symptoms among workers with different job ranks, we hope to add to existing knowledge by showing that - left untreated - psychiatric problems can increase unemployment risk (e.g. McGee and Thompson, 2015; Lerner et al. 2004). Lerner et al. 's (2004) longitudinal study of workers compared baseline and six-month follow-up data from depressed workers with data from a control group of healthy workers and a group with 
non-psychiatric symptoms. Workers with depression had worse employment outcomes than both comparison groups. At the 6-month follow-up, depressed workers were more likely to be unemployed, change to a lower paid job, suffer limits in occupational ability, or be absent from work. Psychiatric symptoms impair job performance (Kamau, 2016, 2017a). Understanding their prevalence among different types of workers can inform supportive interventions.

\section{Objectives}

Evidence shows that low occupational and socioeconomic status are associated with poor mental health but there is a gap in evidence about the incidence of specific psychiatric symptoms. We assessed the associations among job rank, socioeconomic status and symptoms such as depression, avoidance and paranoia as well as physical health. Second, while there is evidence that shows that low socioeconomic status relates to poor mental and physical health, there is little research that measures both socioeconomic status (e.g. gross income and social class) and occupational status (job rank). In this article, we report the unique contributions of each type of status to variance in the incidence of psychiatric symptoms among workers.

\section{Methods}

We analyzed a dataset comprising 8,580 people who took part in extensive assessment interviews for the Psychiatric Morbidity among Adults in Private Households Survey by the 
UK Office for National Statistics (ONS, 2003) between March and September 2000 in England, Wales and Scotland. The survey was sponsored by the Department of Health, the Scottish Executive's Health Department and the National Assembly for Wales. The purpose of the survey was to measure the prevalence of psychiatric symptoms and disorders in the general UK adult population (ages 16 to 74 years) in two stages. Participation in all interviews was voluntary and conducted under ethical guidelines stipulated by the regional health committees granting ethical approval (the London Multi-Centre Research Ethics Committee and 149 local research ethics committees).

Stage 1 interviews: The ONS conducted a stratified multi-stage random probability sample of postal addresses. The ONS then sent a letter to each selected address explaining that it had been chosen for a survey and that interviewers would be visiting to ask if they would like to take part in the survey. After this, interviewers visited the selected addresses to randomly select one person from each residential household aged 16-74 years. From the 12,792 residential addresses visited, $69.5 \%$ adults $(8,886)$ agreed to participate; of these, 8,450 interviews $(98.5 \%)$ were complete and $130(1.5 \%)$ partially complete (totaling 8,580 ). Each consenting person took part in a computer-assisted questionnaire interview with an ONS researcher for an average of 115 minutes. All respondents were asked whether they were willing to take part in second-stage interviews. Stage 1 interviews assessed the following:

- Psychotic disorders were screened for by assessing whether respondents met one of the following criteria: a) current anti-psychotic medication use; b) a history of admission into a psychiatric ward or hospital; c) reporting a psychotic diagnosis such as schizophrenia when asked about long-standing illnesses or when asked about reasons for visiting a 
doctor they gave reasons suggesting that they had experienced psychotic symptoms; and (d) having had auditory hallucinations within the past year, as assessed by an item within the Psychosis Screening Questionnaire (PSQ; Bebbington and Nayani, 1995).

- Mood Disorders formerly known as Neurotic Disorders were assessed using the Revised Clinical Interview Schedule (CIS-R; Lewis and Pelosi, 1990; Lewis, Perosi, Araya and Dunne, 1992) which has 14 sections assessing anxiety; compulsions; concentration/forgetfulness; depression; depressive ideas; fatigue; irritability; obsessions; panic; phobias; sleep problems; worry about physical health; worry; and somatic symptoms. To screen for a neurotic disorder, the ONS applied an algorithm to respondents' data based on 1CD-10 diagnostic criteria (World Health Organization, 1993). This determined the following diagnoses: depressive episodes, generalized anxiety disorder, mixed anxiety and depressive disorder, obsessive-compulsive disorder, panic and phobias,

- Alcohol misuse was assessed using the Alcohol Use Disorders Identification Test (AUDIT; Babor et al., 1992); and the Severity of Alcohol Dependence Questionnaire (SAD-Q; Stockwell, Murphy and Hogson, 1983).

- Drug misuse was assessed using questions about frequency of use, dependence and withdrawal symptoms from amphetamines, cannabis, cocaine, crack, ecstasy, tranquillizers and opiates.

- Personality disorders were assessed using a self-completed screening version of the Structured Clinical Interview for DSM-IV Axis II, Personality Disorders: avoidant; antisocial; borderline; dependent; depressive; histrionic; narcissistic; obsessive- 
compulsive; paranoid; passive-aggressive; schizoid; and schizotypal personality disorders (SCID-II; First et al., 1997).

- General and occupational health using the SF-12 Health Survey (Ware, Kosinski, and Keller, 1996).

- Suicidal ideation and suicide attempts were assessed using CIS-R items (Lewis and Pelosi, 1990; Lewis, Perosi, Araya and Dunne, 1992).

- Other elements of the stage 1 interviews assessed:

- Demographics e.g. age, education

- Employment

- Socioeconomic variables e.g. income and social class

- Accommodation, social networks and support

- Stressful life events

- Intellectual functioning

The current study: For this article, we analyzed data from all 4,596 employed respondents who took part in stage 1 interviews, of which 939 (20.4\%) employees were managers, $739(16 \%) \quad$ employees were supervisors, and 2,918 (63.5\%) employees had lower job ranks. Table 1 presents a summary of respondents' demographics. Insert Table 1

We examined the workers' responses to assessments of the following variables during stage 1 interviews: 
General and occupational health assessment: The respondents were asked about their general health, life event history and their use of health services. General and occupational health was assessed using the SF-12 Health Survey; previous literature shows that it has good reliability (e.g. Ware, Kosinski, and Keller, 1996). In this article, we analyzed the following individual items from the SF-12 measuring general and occupational health: SF1 (general health); SF4 (occupational impairments due to physical health in the past 4 weeks); SF5 (impairments in types of work/activities the respondent can do in the past 4 weeks); SF6 (low productivity at work/activities due to emotional problems); and SF8 (pain has interfered with work). Other SF-12 items were not analyzed for the current study because they lack direct relevance to employment in their wording e.g. items about difficulty climbing stairs, hobbies, and general mood. Factor analysis of all SF items showed that the selected items load onto one factor and analysis of the selected SF items alone confirmed that they represent one factor with only one component having an Eigenvalue greater than $1(E=2.37)$.

Socioeconomic variable assessment: (i) Social class was assessed by the ONS using standard occupational classifications (OPCS, 1991). Each respondent's occupation led the ONS to classify them into one of 5 groups: I (professional); II (intermediate occupations); IIIM (skilled non-manual occupations); IIINM (skilled manual occupations); IV (partly skilled occupations); V (unskilled occupations), all excluding army occupations. (ii) Socioeconomic status was assessed by the ONS based on Standard Occupational Classification (OPCS, 1991) by allocating respondents to one of 14 socioeconomic groups based on their profession, ranging from higher managerial to unemployed. (iii) Household gross income group and (iv) personal gross income group were both assessed by the ONS using 32 income categories that 
it created based on a respondent's income before taxes and national insurance. The categories ranged from 1 (an annual income $<£ 520$ ), 2 (an annual income of $£ 520$ to $£ 1,039$ ), and so on until 32 (an annual income of $\geq 36,400$ ). Measures of socioeconomic factors presented good concurrent validity with each other (with significant inter-correlations, $p<.001$ ) and with job rank. At $p<.001$ job rank correlated significantly with personal gross income group, $r=.48$; household gross income group, $r=.25$; socioeconomic group, $r=-.65$; and social class, $r=-$ .51. A linear regression model showed that the four socioeconomic indicators predicted $46.9 \%$ of the variance in job rank, $R=.69, F(4,3004)=663.84, p<.001$.

Assessment of depressive symptoms and disorders: ONS interviewers used the CIS-R (Lewis et al., 1992) described earlier. They recorded respondents' symptoms over the 1-week period before the interview date capturing symptom frequency, duration, severity and time since onset.

Assessment of paranoia symptoms and paranoid personality disorder: All respondents were screened for the presence of psychosis using the Psychosis Screening Questionnaire (Bebbington \& Nayani, 1994). The PSQ has 5 sections to identify psychotic-like experiences that may have occurred within the past year: hypomania, thought control, paranoia, strange experiences, and hallucinations. Each section has an initial question followed by 1 or 2 follow-up questions to determine severity. For the purposes of the present study, only the paranoia section was of interest particularly the questions asking whether they felt people were against and deliberately trying to harm them. The highest severity of paranoia was 
assessed using the third paranoia criterion question "Have there been times that you felt that a group of people was plotting to cause you serious harm or injury?'”.

Paranoid Personality Disorder was measured by the SCID (Axis II Interview). The DSM-IV defines Paranoid Personality disorder (PPD) as "A pervasive distrust and suspiciousness of others such that their motives are interpreted as malevolent, beginning by early adulthood and present in a variety of contexts" (APA, 1994, page 600), as indicated by four (or more) of the following: (1) suspects without sufficient basis, that others are exploiting, harming and or deceiving them; (2) is preoccupied with unjustifed doubts about the loyalty of friends and associates; (3) is reluctant to confide in others because of unwarranted fear that the information will be used maliciously against him or her; (4) reads hidden demeaning or threatening meanings into benign remarks or events; (5) persistently bears grudges, i.e., is unforgiving of insults, injuries, or slights; (6) perceives attacks on his or her character or reputation that are not apparent to others and is quick to react angrily or to counterattack and (7)has recurrent suspicions, without justification, regarding fidelity of spouse or sexual partner. To be diagnosed with PPD respondents have to report 4 or more of the criteria listed above.

Avoidance symptoms and Avoidant Personality Disorder: Avoidance symptoms and Avoidant Personality Disorder were measured by the SCID (Axis II) Interview. The DSM-IV defines Avoidant Personality Disorder as "A pervasive pattern of social inhibition, feelings of inadequacy, and hypersensitivity to negative evaluation, beginning by early adulthood and present in a variety of contexts" (APA, 1994, page 700). The clinically trained interviewers had to make a judgment of the rating for each item on a four-point scale: 'inadequate 
information', 'negative', 'sub-threshold', and 'threshold'. Each criterion was explored in turn with standard probes and thresholds for marking a criterion as present. To be diagnosed with an Avoidant Personality Disorder, the respondent needed to show 4 or more of the following: 1) avoids occupational activities that involve significant interpersonal contact, because of fears of criticism, disapproval, or rejection; 2) is unwilling to get involved with people unless certain of being liked; 3) shows restraint within intimate relationships because of the fear of being shamed or ridiculed; 4) is preoccupied with being criticized or rejected in social situations; 5) is inhibited in new interpersonal situations because of feelings of inadequacy; 6) views self as socially inept, personally unappealing, or inferior to others; 7) is unusually reluctant to take personal risks or to engage in any new activities because they may prove embarrassing. For the purpose of this study we focused on the presence of avoidant symptoms (criterion 1, 2, 5 and 7) in the sample of workers. It is noteworthy that participants may be showing symptoms of avoidance but do not necessarily meet the criteria for an avoidant personality disorder, so we do not report analyses for the prevalence of Avoidant Personality disorder but focus solely on the presence of avoidance symptoms. To meet the criteria for an Avoidant Personality Disorder, participants need to show 4 or more of the symptoms listed above.

Insert Figure 1

\section{Data analysis}

We analysed the data using SPSS v.20. We calculated the percentages of employees reporting different categories of general health and occupational health. We then examined the 
percentages of employees who report psychiatric symptoms and the percentages with symptoms severe enough to be clinically significant in meeting diagnostic criteria for the relevant psychiatric disorder. We analysed how socioeconomic indicators (including job rank) explain variance in general health, occupational health and psychiatric symptoms using regression models. We then analysed the association between job rank and psychiatric symptoms using a non-parametric test (Kruskal-Wallis) and further assessed how job rank, general health and occupational health explain variance in psychiatric symptoms using regression models.

\section{Results}

Employees' general and occupational health: Of the 4,596 workers, only $494(10.72 \%)$ workers reported fair or poor health, and the rest of the workers reported excellent, very good or good health. Only $11(0.23 \%)$ workers reported that medication impairs their ability to do their job. There were $572(12.45 \%)$ workers who reported that the state of their health has resulted in less work or regular activities. There were $583(12.68 \%)$ workers who reported that health has limited the sorts of work or activities that they can do. There were 545 $(11.86 \%)$ workers who reported that emotional problems have resulted in less work or regular activities. There were 275 (5.98\%) workers who reported that pain has impaired their normal work extremely or quite a bit. In terms of somatic symptoms, only 430 (9.36\%) workers received a score of between 1 and 4 , and the rest received a score of 0 .

Employees' psychotic and non-psychotic symptoms: As expected, the incidence of symptoms of mood disorders was greater than the incidence of more serious psychiatric symptoms and 
diagnoses (psychosis and personality disorders) (see table 2). A score of less than 12 indicated the presence of non-clinically significant symptoms. For the sub-sample of 4,596 employees in the week prior to interview, most adults $(84.9 \%)$ were in this category. Among the $15.1 \%$ of adults scoring 12 or more, $7.5 \%$ were in the range $12-17$ indicating a level of symptoms that was significant, but unlikely to warrant treatment. The other half $(7.5 \%)$ had symptoms of a level of severity likely to require treatment. $9 \%$ of the people with a neurotic disorder presented with mixed anxiety and depressive disorder. Women were more likely than men to have depressive episodes ( $2.5 \%$ vs. $1.9 \%$ respectively). In contrast to this, the overall prevalence of psychotic disorders in this sub-sample was $0.4 \%(0.3 \%$ of men, $0.5 \%$ of women). In both men and women, the highest prevalence was observed in those aged 35 to 44 years $(0.7 \%$ and $1.1 \%$ respectively).

Moreover in the sub-sample of the 4,596 workers, 2,463 (53.6\%) had depressive symptoms and $2,133(46.4 \%)$ no depressive symptoms on the CIS-R. Out of the 4,596 workers 330 (7.1\%) were signalled as having symptoms of less common and more severe psychiatric disorders, namely psychotic and personality disorders e.g. avoidant personality disorder and paranoid personality disorder. Out of 330 workers, $256(78 \%)$ workers met 0 criteria for paranoid personality disorder.

Also, of the 330 workers, $74(22.4 \%)$ respondents met between 1 and 6 criteria for paranoid personality disorder, and $73(22.1 \%)$ for avoidant symptoms on the SCID II (see table 2 for a full description). 
Socioeconomic indicators and variance in general and occupational health: Linear regression models tested the association between job rank, household gross income, social class, personal gross income and socio-economic group on each of the following criterion variables that indicate general and occupational health, with table 3 showing the unique effect of each predictor: (1) general health, $R=.13, F(5,3002)=10.11, p=.001$; variables significantly associated with general health were household gross income and socioeconomic group, $p<.05$. (2) Impact of health on work, $R=.07, F(5,3002)=2.62, p=.023$; variables significantly associated with this were social class, personal gross income group and socioeconomic group, $p<.05$. (3) Limiting impact of health on work, $R=.04, F(5,3003)=$ 1.17, $\mathrm{p}=0.323$ (n.s.) (4) Emotional problems limiting work, $R=.08, F(5,3003)=3.51, p$ $=.004$; variables significantly associated with this were the significant unique predictor was personal gross income, $p=.025$. (5) Pain interfering with work, $R=.07, F(5,3001)=2.52, p$ $=.027$; variables significantly associated with this were household gross income was the significant unique predictor, $p=.043$. (6) Somatic symptoms, $R=.08, F(5,3003)=3.54, p$ $=.003$; variables significantly associated with this were socioeconomic group, $p=.032$.

Socioeconomic indicators and variance in psychotic/non-psychotic symptoms: Linear regression showed that job rank, household gross income group, social class, personal gross income group and socio-economic group were significantly associated with depressive symptoms, $R=.10, F(5,3003)=5.70, p=.001$. Depressive symptoms were significantly associated with personal gross income group, socioeconomic group, and social class, $p<.05$. Job rank and household gross income group were not significantly associated with depressive 
symptoms. Linear regression showed that job rank, household gross income group, social class, personal gross income group and socio-economic group were significantly associated with the presence of avoidant symptoms, $R=.27, F(5,229)=3.54, p=.004 ; t$ tests showed that only household gross income was uniquely associated with avoidant symptoms, $p=.015$. On the other hand, paranoia symptoms were not significantly associated with job rank, household gross income, social class, personal gross income and socio-economic group on paranoia among workers, $R=.19, F(5,229)=1.62$, n.s.

Insert Table 3

Job rank, occupational health and psychotic symptoms: Kruskal-Wallis tests were performed to examine the effects of job rank on paranoia and avoidant criteria. A Kruskal-Wallis test showed a statistically significant effect of job rank on the paranoid criteria $(H(2)=10.09, p$ $=.006$ ), with managers reporting the lowest number of paranoia criteria, supervisors the second-lowest, and lower rank workers the highest count $\left(M_{\text {(managers) }}=2.63, S D_{\text {(managers) }}=\right.$ $1.19, M_{\text {(foremen) }}=3.09, S D_{(\text {foremen) }}=1.70, M_{\text {(non-managers/non-foremen) }}=4.16, S D$ (non-managers/non-foremen) $=1.86$ ). A further Kruskal-Wallis test showed that job rank had also an effect on avoidant personality disorder criteria of the SCID II $(H(2)=44.52, p<.001)$, with managers reporting the lowest, supervisors the second-lowest and lower rank workers the highest count of avoidant criteria $\left(M_{\text {(managers) }}=1.82, S D_{\text {(managers) }}=1.47, M_{\text {(foremen) }}=3.13, S D_{\text {(foremen) }}=1.96, M\right.$ (non-managers/non-foremen) $=3.75, S D$ (non-managers/non-foremen) $=2.04)$. Regressing job rank, occupational and physical health onto paranoia criteria showed a significant effect, $R=.30, F(7,320)=$ $4.54, p=.000$. Paranoia criteria were significantly associated with general health, emotional problems and job rank, $p<.05$. Testing avoidant criteria as the criterion variable showed 
likewise, $R=.31, F(7,320)=5.01, p=.001$, there were significant associations with general health, health reducing work, health limiting work and job rank, $p<.05$. This showed that paranoia and avoidant symptoms are associated with job rank and occupational health. In other words, the lower the job rank the more likely the presence of paranoia and avoidant symptoms, indicating vulnerability to more severe psychopathology including psychosis and personality disorders (e.g., paranoid schizophrenia and avoidant and paranoid personality disorders).

\section{Discussion}

In understanding the epidemiology of community mental health, our results show that an important consideration is a person's job rank, health problems associated with their job, and their socio-economic status.

This study found that socio-economic factors are associated with mental health outcomes, namely with the presence of depressive symptoms and poor physical health in a sample of UK workers, but it also shows that paranoia, a symptom most commonly seen in psychotic disorders, does not appear to be associated with socio-economic factors, such as social class, socio-economic group and personal income. Rather, paranoia has a strong association with job rank and occupational health, such as emotional problems impacting work. This suggests that there is no direct association between socio-economic factors and more severe forms of psychopathology. Although socio-economic factors are related to occupational health, it appears that the relationship between socio-economic factors and paranoia may be more complex than that observed between socio-economic factors and 
mood- related disorders. Occupational health may mediate this relationship. This makes an important contribution to existing theory and epidemiological research on community mental health, which generally posits that low socio-economic background and low income may be conducive to psychopathology and poor health (Calixto \& Anaya, 2014; Marmot \& Smith, 1991). This research highlights the complexity of this issue - coupling socio-economic factors with poor health can shed greater light on the development of psychopathology among workers.

Our research shows that depressive symptoms such as panic, depressive ideas and obsessions are associated with socio-economic factors such as low income (Calixto \& Anaya, 2014). Previous research suggests that socio-economic status is an important determinant of one's physical and mental well-being (Adler et al.,1994; Winkleby et al., 1992). On the other hand, more severe forms of psychopathology, such as paranoia and avoidant personalities are associated with job rank and occupational health. Although the cross-sectional nature of this research precludes claims regarding causality, it is possible that paranoia and avoidance constitute adaptive reactions to the circumstances of low power experienced by workers in non-managerial and non-supervisory jobs. Indeed, the results suggest that paranoia and avoidant symptoms are more prevalent in low rank workers than in workers in managerial or supervisory jobs. Previous empirical work shows that power differentials at work, socioeconomic factors and low rank cause poorer health, unhealthy functioning and general impairment (Marmot \& Smith, 1991). Moreover, the findings suggest that power differentials at work are related to occupational health (limiting work and other activities and producing emotional issues at work) (Marmot \& Smith, 1991; Lerner et al., 2004), which could in turn increase vulnerability to more severe forms of psychopathology (de Graaf, 1997). 
These results also support previous literature about the established relationship between low social rank and paranoid ideation (Gilbert, 2001; Gilbert et al., 2005; Lopes, 2011). Evolutionary theorists have been arguing that low rank individuals learn to fear and to avoid other people in order to steer clear of harm (Gilbert, 2001; Gilbert et al., 2005). The present study suggests that the same principle may apply to workplace rank. People with a low job rank may view the workplace as a threatening context, which can explain a general disengagement and avoidance, which in turn is typical of avoidant and paranoid personalities (Carrol, 2009). Yet, the workplace is also a social context which cannot be easily avoided due to people's dependence on it for their livelihoods. Individuals may be socially obligated to develop strategies for coping. Previous research shows that the aforementioned reactions can constitute adaptive ways of coping with the social threats associated with having a low rank (Gilbert, 1992; Gilbert, 2001; Gilbert et al., 2005; Lopes, 2011). People may perceive them as a means of avoiding conflict and potential harm - both social and psychological - by developing avoidant personality traits. These are, thus, essentially disengagement strategies. The development of avoidant personality traits allows the low job rank individual to continue to function psychologically in an inherently threatening context. Moreover, high sensitivity to threat in the form of paranoia about malevolent behaviors from higher rank individuals can be adaptive among people with non-managerial or supervisory jobs. Indeed, feeling paranoid about what higher rank individuals will do to you may be an adaptive strategy formed to deal with social situations and experiences of abuse and bullying by managers (Kramer, 1999). Furthermore, avoiding potential conflict is perceived as minimizing the likelihood of being harmed or loosing benefits e.g., being fired. Thus, from the perspective of a subordinate, it is better to "be safe than sorry" (Gilbert, 1992). 
It is noteworthy that our results support studies showing that paranoia and an avoidant personality disorder are comorbid and prevalent in low rank individuals (Carrol, 2009). Both are characterized by a degree of mistrust of other people and consequential social withdrawal. Avoidant people tend to lack confidence and tend to believe that they will perform inadequately in certain social situations (Carrol, 2009) and as such they will fail to move up the ranks because they avoid going for promotions, etc. Is it possible that avoidant personality traits could - together with paranoia ("I have to watch my back since the manager is not to be trusted") - constitute an adaptive preventative mechanism in a workplace?

All in all, this may contribute to theory and research on how self-identity processes and self-protection mechanisms enable people to cope with threatening social situations (Jaspal \& Breakwell, 2014), but it also alerts us to important contributions of evolutionary psychology to understanding the presence of psychopathology in the workplace. This preliminary cross-sectional study, which does not allow for causal assertions, does nonetheless demonstrate the need for integrating distinct paradigms and subdisciplines of psychology in order to understand the nature of the complex associations between workplace rank and paranoid psychopathology.

Although paranoid and avoidant strategies may be effective in dealing with social contexts of conflict and competition at work, they are maladaptive in the long term, potentially leading to the development of psychopathology (Kramer, 1999; Gilbert, 2001). Indeed, when these mechanisms are in place, they become dysfunctional as the individual may be unable to develop self-confidence, self-esteem and resilience (Lopes, 2011). These are of course important principles of identity development and psychological well-being (Jaspal \& Breakwell, 2014). 
Although this study was conducted in 2000, 2015/16 data from the UK's Labour Force Survey (Health and Safety Executive, 2016) shows that the prevalence and incidence of depression, anxiety and other common psychiatric conditions remains broadly similar to what was observed in the 2000 sample. Indeed, the 2015/16 data showed a prevalence among UK workers of common psychiatric disorders like depression and anxiety of around 1,510 per 100,000 workers and an incidence of 690 per 100,000, which suggested that the estimated rate of common psychiatric problems has remained much the same for over two decades in the UK (Health and Safety Executive, 2016). Some authors suggest a worsening of common mental health problems among some age groups between the years 2007 and 2014 because of the economic recession (Stansfeld, Clark, Bebbington, King, Jenkins, Hinchcliffe, 2016) therefore the psychiatric symptoms we observed in the 2000 sample are likely to have remained level or worsened since. There have, however, been improvements in how people can access support for mental health problems because in 2008 the UK government established the Improving Access to Psychological Problems Therapies (IAPT) programme, a scheme within the freely accessible National Health Service (NHS). It has helped improve public access to treatments such as Cognitive and Behavioural Therapy but some authors (e.g. Harvey, Handerson, Lelliott \& Hotopf, 2009) argue that IAPT may not be as effective in helping people with common mental health problems resume employment because many IAPT services do not have employment support as a treatment pathway and IAPT schemes such as the "Pathways to work Programme" could be improved. Researchers also argue that there is no standardized return-to-work or employment support scheme embedded within NHS mental health services (Kamau 2016, 2017a; Harvey et al., 2009) and that, in spite of the social inclusion rhetoric, secondary services are still very much oriented towards crisis 
care and risk management of those with severe mental health problems (Harvey et al., 2009). For instance, a study by Kamau (2016) of 3,329 adult clients of the NHS mental health service interested in employment support (e.g. appropriate information or signposting about returning to work) did not receive the support. The study found that people taking medication for a mental illness are significantly more likely to receive the support because selective serotonin reuptake inhibitors, benzodiazepines and other common prescriptions impair workplace performance through impaired cognitive processing, memory and perception, by causing drowsiness, confusion or fatigue, and by increasing accident proneness (Smith, Wadsworth \& Moss et al. 2004) but argued that people recovering from a mental illness without taking medication still need employment support. A major obstacle is therefore that NHS occupational rehabilitation programmes in the UK are still poorly developed and unevenly distributed geographically (Harvey et al., 2009).

We recommend that NHS mental health services (and similar services in other countries) developing employment support programmes for workers coping with psychiatric symptoms use our findings in three main ways. First, we recommend that training programmes for psychiatric staff (e.g. care programme approach training, Kamau, 2014) improve their awareness about how job rank and other socioeconomic factors are associated with psychiatric symptoms. Second, we recommend that psychiatric staff designing employment support (specifically, individual placement and support programmes also known as supported employment schemes) consider whether or not a client's assigned job rank will contribute to worse symptoms. Third, we recommend that psychiatric staff provide employment support to not just working clients diagnosed with a psychiatric disorder but also workers presenting psychiatric symptoms that are occupationally relevant in that they lead the worker to seek 
help or advice from their family doctor or other clinician because of occupational impairment. For example, statistics showing that depression is the most prevalent mental disorder among working-age adults in the UK and causes the most occupational impairment (Lelliot, Tulloch \& Boardman et al. 2008; Fournir, DeRubeis \& Amsterdam et al. 2015) but not all workers presenting with depressive symptoms that cause occupational impairments may meet the criteria for major depressive disorder - but this does not mean that they would not benefit from employment support schemes run by the NHS. We recommend integrating employment support into regular mental health treatment because e.g. Lagerveld, Blonk, \& Brenninkmeijer et al. (2012) found that work-focused CBT administered to employees on long-term sick leave because of a psychiatric disorder led to them returning to work 65 days sooner and having less severe symptoms than employees getting regular CBT.

There is also still much work to be done by many organisations in the UK in safeguarding the mental health of their workers. We recommend that organisations explore endemic and persistent issues that workers feel contribute to mental health problems such as workload pressures, tight deadlines, too much responsibility and lack of managerial support (Health and Safety Executive, 2016). We therefore recommend that organisations initiate mental health awareness-raising campaigns for their workers, provide confidential employee assistance programs to reduce the presence of mental health symptoms (e.g., depressive symptoms, see Lorant et al., 2003), and be aware of how they as organisations can supplement NHS mental health services in offering support for workers returning to work with a mental illness. We also recommend that organisations improve provision for workers with mental health problems within existing occupational health services. For example, provision for pregnant workers and those returning from maternity leave should include 
information, advice and signposting about postpartum depression or psychosis (which is not adequately supported by the NHS, Kamau, 2017a). We also encourage organisations to be aware of the interaction between physical health and mental health; for example, support for workers recovering from cancer should include mental health support (Kamau, 2017b).

Future research should test the effectiveness of these recommendations and other ways that our current findings can help psychiatric staff, mental health services and organizations provide better support for workers with psychiatric disorders and symptoms. Future research should also explore whether demand characteristics play a role in explaining some of the variance in psychiatric symptoms associated with job rank. Managers and supervisors might feel under pressure to present 'normal' mental health and they may withhold their true responses to questions about panic, depressive ideas, and so on. People with the tendency to impression manage what others think of them tend to be successful at rising in job rank (Anderson \& Brown, 2010; Cheng et al., 2010; Morf \& Rhodewalt, 2001) and thus there is somewhat a 'Catch $22^{\prime}$ in how to accurately diagnose a high ranking worker. In addition, because this is a cross-sectional study, it may well be that people with avoidant personalities may be drawn to lower rank positions in their jobs and not the other way around. Future research should therefore use longitudinal designs to measure how these symptoms develop progressively over time.

In conclusion, we have found that job rank and socioeconomic factors explain variance in workers' general health, occupational health and psychiatric symptoms. This is among the first studies to show that the lower the job rank, the worse a worker's psychiatric symptoms: for example, we have found that ordinary workers present more paranoid symptoms and avoidant personality disorder symptoms than supervisory workers, who in turn 
present more symptoms than managerial workers. We hope that this article will stimulate additional new research into the epidemiology of workers' mental health.

Conflicts of interest: The authors declare no conflicts of interest.

\section{References}

Adler, NE; Boyce, T; Chesney MA; Cohen S; Folkman S; Khan, RL \& Syme, SL (1994) Socio-economic status and health. The challenge of the gradient. American Psychologist, 49, (1), $15-24$

American Psychiatric Association (APA) (1994) Diagnostic and Statistic Manual of Mental Disorders (DSM). American Psychiatric Association Publications. USA

Anderson, C., \& Brown, C. E. (2010). The functions and dysfunctions of hierarchy. Research in Organizational Behavior, 30, 55-89.

Babor T.F., Higgins-Biddle J.C., Saunders J.B. \& Monteiro M.G. (1992) The Alcohol Use Disorders Identification Test (AUDIT) Guidelines for Use in Primary Care. World Health Organization. Department of Mental Health and Substance Dependence.

Bass, B. M. (1998). Transformational leadership: Industrial, military, and educational impact. Mahwah, NJ: Erlbaum. 
Bebbington P., Nayani T. (1995) The Psychosis Screening Questionnaire. International Journal of Methods Psychiatric Research,5,11-19

Bentall R. P., Kinderman P., \& Kaney S. (1994). The self, attributional processes and abnormal beliefs: Towards a model of persecutory delusions. Behaviour Research and Therapy, 32, 331-341

Bentall R. P., Wickham S., Shevlin M. \& Varese F. (2012) Do Specific Early-Life Adversities Lead to Specific Symptoms of Psychosis? A Study from the 2007 The Adult Psychiatric Morbidity Survey. Schizophrenia Bulletin, 1-7. doi:10.1093/schbul/sbs049

Bowlby J. (1988). A Secure Base: Clinical Applications of Attachment Theory. London: Routledge.

Breakwell, G. (1986) Coping with Threatening Identities. Methuen \& Co. Ltd., London

Brugha T. S., Bebbington P. E., Jenkins R., Meltzer H., Taub N.A., Janas M., Vernon J. Cross (1999) Validation of a general population survey diagnostic interview: a comparison of CIS-R with SCAN ICD-10 diagnostic categories. Psychological Medicine,24,16-27

Calixto, O. J., \& Anaya, J. M. (2014). Socioeconomic status: the relationship with health and autoimmune diseases. Autoimmunity Reviews, 13(6), 641-654 
Carroll, A. (2009). Are you looking at me? Understanding and managing Paranoid Personality Disorder. Advances in Psychiatric Treatment, 15, 40-48

Cheng, J.T., Tracy, J. L. \& Henrich, J. (2010). Pride, Personality, and the evolutionary foundations of human social status. Evolution and Human Behaviour, 31, 334-347

Conway, D.L., Petticrew, M., Marlborough, H., Berthiller, J., Hashibe, M. \& MacPherson, L.M.D. (2008). Socioeconomic inequalities and oral cancer risk: A systematic review and meta-analysis of case-control studies. International Journal of Cancer, 122, 2811-2819 Costa-Font, J., Hernández-Quevedo, C., \& Jiménez-Rubio, D. (2014). Income inequalities in unhealthy life styles in England and Spain. Economics and Human Biology, 13, 66-75

Cottini, E. (2012). Health at work and low pay: A European Perspective. The Manchester School, 80(1), 75-98

de Graaf R. , Bijl R.V., ten Have M. et al. (2004) Pathways to comorbidity: the transition of pure mood, anxiety and substance use disorders into comorbid conditions in a longitudinal population-based study. Journal of Affective Disorders, 82, 461-7

Demakakos, P., Nazroo, J., Breeze, E., \& Marmot, M. (2008). Socioeconomic status and health: the role of subjective social status. Social Science and Medicine, 67(2), 330-340 
Edinger, J. A. \& Patterson, M. L. (1983) Nonverbal involvement and social control. Psychological Bulletin, 93, 30-56

Feinstein, J. S. (1993). The relationship between socioeconomic status and health: a review of the literature. The Milbank Quarterly, 71(2), 279-322

First, M.B., Gibbon M., Spitzer R. L., Williams, J.B.W., Benjamin L. S. (1997) Structured Clinical Interview for DSM-IV Axis II Personality Disorders, (SCID-II). Washington, D.C.: American Psychiatric Press, Inc,

Fournier, J.C., DeRubeis, R.J, Amsterdam, J. Shelton, R.C., Hollon, S.D. (2015). Gains in employment status following antidepressant medication or cognitive therapy for depression. British Journal of Psychiatry, 206, 332-338.

Freeman, D., Garety, P., Kuipers, E., Fowler, D. \& Bebbington, P. (2002). A cognitive model of persecutory delusions. British Journal of Clinical Psychology, 41, 331-347

Freeman, D.; Garety, P.; Bebbington, P.; Smith, B.; Rollinson, R. \& Fowler, D. (2005). Psychological investigation of the structure of paranoia in a non-clinical population. British Journal of Psychiatry, 16, 427-435

George, D., \& Mallery, M. (2010). SPSS for Windows Step by Step: A Simple Guide and Reference, 17.0 update (10a ed.) Boston: Pearson. 
Gilbert, P. (1992). Depression: The evolution of powerlessness. New York: Guilford Press, USA.

Gilbert, P. (1993). Defence and safety: their function in social behaviour and psychopathology. British Journal of Clinical Psychology, 32, 131-153

Gilbert, P. (2001). Evolutionary approaches to psychopathology: The role of natural defences. Australian \& New Zealand Journal of Psychiatry, 35, 17-27.

Gilbert P., Boxall M., Cheung M. \& Irons C. (2005). The relation of Paranoid Ideation and Social Anxiety in a Mixed population, Clinical Psychology and Psychoterapy, 12, 124-133

Gilbert P., Gilbert J. \& Irons C. (2004). Life events, entrapments and arrested anger in depression. Journal of Affective Disorders, 79, 149-160.

Goldthorpe, J. H. (1997) 'The "Goldthorpe" class schema: some observations on conceptual and operational issues in relation to the ESRC review of government social classifications' in D. Rose and K. O'Reilly (Eds.) Constructing Classes. Swindon and London: ESRC and ONS. Hart, S. D., Cox, D. N., \& Hare, R. D. (1995). Manual for the Psychopathy ChecklistScreening Version. Toronto, Canada: Multi-Health Systems 
Published in Community Mental Health Journal, 54, 1-14

https://doi.org/10.1007/s1059

Harvey, S.; Henderson, M.; Lelliott, P. \& Hotopf, M. (2009) Mental Health and Unemployment: Much work still to be done. The British Journal of Psychiatry, 194, 201-203. doi: 10.1192/bjp.bp.108.055111

Health and Safety Executive (2016) Work-Related Stress, Depression and Anxiety Statistics in the UK. National Statistics: www.hse.gov.uk/statistics/

Jaspal, R. \& Breakwell, G.M. (2014). Identity Process Theory: Identity, Social Action and Social Change. Cambridge: Cambridge University Press.

Kamau, C. (2014). Outcomes of care programme approach, dual diagnosis, carer support and psychological therapy inductions. Psychiatric Bulletin, 38, 172-174.

Kamau, C. (2016). Is the NHS mental health service preparing clients to resume employment? Psychiatric Services, 67, 578-579

Kamau, C. (2017a). Postpartum depression or psychosis and return to work. Lancet Psychiatry, 4(2), 96-97.

Kamau, C. (2017b). Preparing patients with cancer who work and treatment responsiveness. BMJ Supportive and Palliative Care, 7, 94-97.

Kramer, R. M. (1994) The sinister attribution error: Paranoid cognition and collective distrust in organizations. Motivation and Emotion, 18, 199-230. 
Kramer, R. M. (1999) Trust and distrust in organizations: Emerging perspectives, enduring questions. Annual Review of Psychology, 50, 569-598.

Kroenke K., Spitzer R. L., Williams J. B. (2001)The PHQ-9: validity of a brief depression severity measure. Journal of General Internal Medicine; 16, 606-613.

Lagerveld, S. E., Blonk, R. W., Brenninkmeijer, V., Wijngaards-de Meij, L., Schaufeli, W. B. (2012). Work-focused treatment of common mental disorders and return to work: a comparative outcome study. Journal of Occupational Health Psychology, 17, 220-234.

Lelliott O, Tulloch S, Boardman J, et al. (2008). Mental Health and Work. Commissioned by the cross government Health Work and Wellbeing Programme. London, Royal College of Psychiatrists.

Lerner D., Adler D., Chang H., Lapitsky L., Hood M., Perissinotto C., Reed J., McLaughlin T., Berndt E. \& Rogers W. (2004) Unemployment, Job Retention, and Productivity Loss among Employees with Depression. Psychiatric Services, 55 (12), 13711378. doi:10.1176/appi.ps.55.12.1371.

Lewis, G., Pelosi, A. J., Araya, R. C. \& Dunn, G. (1992). Measuring psychiatric disorder in the community: a standardized assessment for use by lay-interviewers. Psychological Medicine, 22, 465-486. 
Lopes, B. (2013) Differences between victims of bullying and non-victims on levels of paranoid ideation and persecutory symptoms, the presence of aggressive traits, the display of social anxiety and the recall of childhood abuse experiences in a Portuguese mixed clinical sample. Clinical Psychology \& Psychotherapy, 20(3), 254-266.

Lorant, V., Croux, C., Weich, S., Deliège, D., Mackenbach, J. \& Ansseau, M. (2007). Depression and socio-economic risk factors: 7-year longitudinal population study. The British Journal of Psychiatry, 190(4), 293-98.

Lorant, V., D, Deliège, Eaton, W., Robert, A., Philippot, P. \& Ansseau, M. (2003). Socioeconomic inequalities in depression: a meta-analysis. American Journal of Epidemiology, 157(2), 98-112.

Marmot, M. (2005). Social determinants of health inequalities. Lancet, 365, 1099-1104

Marmot, M. G.; Rose, G.; Shipley, M.; Hamilton, P. J. (1978). Employment grade and coronary heart disease in British civil servants. Journal of Epidemiology and Community Health 32 (4): 244-249

Marmot, M. G., \& Smith, G. D. (1991). Health inequalities among British civil servants: The Whitehall II study. Lancet, 337(8754), 1387.

Medisauskaite, A. and Kamau, C. (2017). Prevalence of oncologists in distress: systematic review and meta-analysis. Psycho-Oncology, 26, 1732-1740. 
McGee, R. \& Thompson, N. (2015) Unemployment and Depression Among Emerging Adults in 12 States, Behavioural Risk Surveillance Sytem, 2010. Preventing Chronic Disease: Public Health Research, Practice, and Policy. 12, 1-11.

Meltzer, H., Gil,1 B. \& Petticrew, M. (1995). OPCS Surveys of Psychiatric Morbidity in Great Britain. Report No 1. The Prevalence of Psychiatric Morbidity among Adults aged 1664 Living in Private Households in Great Britain. HMSO : London.

Morf, C. \& Rhodewalt, F.(2001) Unraveling the Paradoxes of Narcissism: A dynamic Selfregulatory Model. Psychological Inquiry, 12, 177-196

Murata, K., Nogawa, K., \& Suwazono, Y. (2013). The relationship between job type and development of cerebral stroke in a large, longitudinal cohort study of workers in a railway company in Japan. Atherosclerosis, 229(1), 217-221.

O’ Boyle, H. E., Forsyth, R. D., Banks, C. J. \& McDaniel, M. (2012) A meta-analysis of the Dark Triad and work behavior: A social exchange perspective. Journal of Applied Psychology, 97, 557-579.

Office for National Statistics, Psychiatric Morbidity among Adults Living in Private Households, 2000 [computer file]. Colchester, Essex: UK Data Archive [distributor], May 2003. SN: 4653 , http://dx.doi.org/10.5255/UKDA-SN-4653-1 
Office of Population Censuses and Surveys (1990). Standard Occupational Classification, Vol. 1. HMSO : London.

Rhode, P. Lewinsohn, P.M. \& Seeley, J. (1991) Comorbidity of Unipolar depression: II Comorbidity With other mental disorders in adolescents and adults. Journal of Abnormal Psychology, 100 (2), 214-22.

Schoenbaum M., Unutzer J., Sherbourne C., et al. (2001) Cost-effectiveness of practiceinitiated quality improvement for depression: results of a randomized controlled trial. Journal of the American Medical Association, 286, 1325-1330.

Schoenbaum M., Unutzer J., McCaffrey D., et al. (2002) The effects of primary care depression treatment on patients' clinical status and employment. Health Services Research, $37,1145-1158$.

Shmueli, H., Rogowski, O., Toker, S., Melamed, S., Leshem-Rubinow, E., Ben-Assa, E., Shapira, I., Berliner, S. \& Steinvil, A. (2014). Effect of socioeconomic status on cardiorespiratory fitness: data from a health screening program. Journal of Cardiovascular Medicine, 15(6), 435-440.

Simon G. E., Revicki D., Heiligenstein J., et al. (2000) Recovery from depression, work productivity, and health care costs among primary care patients. General Hospital Psychiatry, $22,153-162$. 
Smith A, Wadsworth E, Moss S, et al. (2004). The scale and impact of psychotropic medication use by workers. Health and Safety Executive: Research Report 282. HSE Books: Crown Copyright.

Stansfeld, S., Clark, C., Bebbington, P., King, M., Jenkins, R., \& Hinchliffe, S. (2016). Chapter 2: Common mental disorders. In S. McManus, P. Bebbington, R. Jenkins, \& T. Brugha (Eds.), Mental health and wellbeing in England: Adult Psychiatric Morbidity Survey 2014. Leeds: NHS Digital.

Stockwell T., Murphy D. \& Hodgson R. (1983) The Severity of Alcohol Dependence Questionnaire: Its Use, Reliability and Validity. Addiction, 78 (2), 145-155 DOI: $10.1111 / \mathrm{j} .1360-0443.1983 . t b 05502 . x$

Thomas, C. \& Morris, S. (2003) Cost of Depression among adults in the UK. British Journal of Psychiatry, 183, 514-519.

Verdoux, H. \& Van Os J. (2002) Psychotic symptoms in non-clinical populations and the continuum of psychosis. Schizophrenia Research, 54 (1), 59-65. 
Ware, J.: Kosinski, M. \& Keller, S.D. (1996) A 12 item Short Form Health Survey: Construction of Scales and preliminary tests of validity and reliability. Medical Care, 34 (3), $220-33$

Wing, J. K., Babor, T., Brugha, T., Burke, J., Cooper, J. E., Giel, R., Jablensky, A., Regier, R. \& Sartorius, N. (1990). SCAN: Schedules for Clinical Assessment in Neuropsychiatry. Archives of General Psychiatry, 47, 589-593.

Winkleby, M. A., Jatulis, D. E., Frank, E., \& Fortmann, S. P. (1992). Socioeconomic status and health: how education, income, and occupation contribute to risk factors for cardiovascular disease. American Journal of Public Health, 82(6), 816-820.

World Health Organization (1993). The ICD-10 Classification of Mental and Behavioural Disorders. Diagnostic Criteria for Research. WHO : Geneva.

World Health Organization Division of Mental Health (1999) SCAN Schedules for Clinical Assessment in Neuropsychiatry Version 2.1, World Health Organization: Geneva.

Zhang M., Rost K. M., Fortney J. C., et al. (1999) A community study of depression treatment and employment earnings. Psychiatric Services, 50, 1209-1213. 
Published in Community Mental Health Journal, 54, 1-14

https://doi.org/10.1007/s1059

Table 1: The workers' demographics

\begin{tabular}{ll}
\hline Works in an organization with $>25$ employees & $65.8 \%(3025)$ \\
\hline $\begin{array}{l}\text { Employees who took }>10 \text { days off from work because } \\
\text { of health in the past year }\end{array}$ & $32.1 \%$ (1477) \\
\hline Mean number of days off from work in the past year & 20.93 (SD=43.05) \\
\hline & I - Professional occupations 5.9\% (273) \\
& $\begin{array}{l}\text { II - Managerial and technical occupations 33.0\% } \\
(1517)\end{array}$ \\
& $\begin{array}{l}\text { IIINM - Skilled non-manual occupations 25.1\% } \\
(1154)\end{array}$ \\
Social class based on occupation & IIIM - Skilled manual occupations 17.1\% (785) \\
& IV - Partly skilled occupations 14.1\% (647) \\
& V - Unskilled occupations 4.5\% (208) \\
\hline Married & Armed forces 0.3\% (12) \\
\hline
\end{tabular}

University degree $22.7 \%$ (862)

A Levels or equivalent $19.7 \%$ (751)

Education

Teaching qualification $9.9 \%$ (377)

Secondary school (O Levels or similar) 41.1\% (1564)

Other/none $6.6 \%(250)$

Have a criminal conviction

$10.3 \%(475)$

Ethnicity

White 94\% (4326) 
Published in Community Mental Health Journal, 54, 1-14

https://doi.org/10.1007/s1059

African or West Indian 2.39\% (110)

Asian $1.63 \%(75)$

Other $1.80 \%(83)$

Personal gross income

Range 1-32 $(M=19.36, S D=7.70)$

Household gross income

Range 1-32 $(M=26.67, S D=5.48)$ 
https://doi.org/10.1007/s1059

Table 2: The workers' psychiatric diagnoses, symptoms and use of mental health services

Workers with $\geq 1$ long-standing illnesses

$36.6 \%$ (1684 workers, of which $2.72 \%$ or 125 have mental disorders)

Anorexia nervosa $0.12 \%(2)$

Anxiety $0.65 \%(11)$

Bulimia 0.18\% (3)

Depression $4.04 \%(68)$

Severe depression $0.12 \%(2)$

Of the workers with $\geq 1$ long-standing illnesses,

Manic depression $0.12 \%(2)$

incidences of chronic mental disorders (ICD-10)

Nervous breakdown $0.06 \%$ (1)

OCD $0.12 \%(2)$

Panic attacks $0.30 \%(5)$

PTSD $0.18 \%(3)$

Sleep walking $0.06 \%$ (1)

Schizoaffective disorder $0.06 \%$ (1)

Stress $1.25 \%(21)$

\begin{tabular}{ll}
\hline Workers taking psychiatric medication & $2.83 \%(130)$ \\
\hline Had suicidal thoughts in lifetime & $14.8 \%(787)$ \\
\hline & $11.01 \%(506)$ \\
$\begin{array}{l}\text { Workers who consulted their family doctor about } \\
\text { mental health problems in the last year }\end{array}$ \\
\hline
\end{tabular}

Workers who had been hospital inpatients in the last

$6.83 \%(314)$ year (medical/other conditions)

Workers who had been hospital outpatients in the $36.05 \%(1657)$ last year 
Somatic 9.4\% (430)

Fatigue $33.7 \%$ (1551)

Poor memory $16.79 \%$ (772)

Irritability $37.6 \%(1728)$

Depression $18.6 \%(853)$

Workers with CISR symptoms score $>0$

Worry $37.1 \%(1706)$

Anxiety $17.8 \%(820)$

Phobia $11.8 \%(547)$

Panic $1.7 \%(76)$

Obsessions 6.5\% (299)

\section{Workers with paranoid symptoms:}

Felt people were against them $23.35 \%$ (233 Managers, 183

Foremen and 657 lower rank workers)

Felt people were deliberately against them 10.1\% (111

Managers, 77 Foremen and 274 lower rank workers)

Workers with psychotic and paranoia symptoms of the PSQ
Felt people were plotting to harm them* $1.26 \%$ (16 Managers, 11 Foremen, 31 lower rank workers)

\section{Workers with psychotic symptoms:}

Felt controlled by an outside force $9.46 \%$ (435)

Heard or saw things others could not $3.83 \%$ (176)

Heard voices with no one around $0.78 \%(36)$
Workers showing Avoidant Personality Disorder ( $4+$ avoidant criteria symptoms on the SCID II)
$N=330$

$1.2 \%$ met 4 avoidant criteria on the SCID II (0 Managers, 2

Foremen and 2 lower rank workers) 
$3.3 \%$ met threshold for avoidant criterion 1 (0 Managers, 1

Foreman and 10 lower rank workers)

3.3\% met threshold for avoidant criterion 2 (1 Manager, 1

Foreman and 9 lower rank workers)

$6.4 \%$ met threshold for avoidant criterion 5 (1 Manager, 5 Foremen an 15 lower rank workers)

$4.2 \%$ met threshold for avoidant criterion 7 (2 Managers, 4 Foremen and 14 lower rank workers)

Workers showing Paranoid Personality Disorder (4+ paranoid criteria on the SCID II)
$N=330$

$77.57 \%$ met 0 symptoms on the SCID II (55 Managers, 49 Foremen and 152 lower rank workers)

$1.2 \%$ met 4 paranoid criteria on the SCID II (0 Managers, 2 Foremen and 2 lower rank workers)

Tobacco $29.09 \%$ (1337)

Alcohol $91.36 \%$ (4199, of which $18.78 \%$ or 863 have $6+$ alcohol drinks weekly and $1.46 \%$ or 67 have them daily)

Amphetamines in the last month $0.48 \%$

Substance use

Cocaine in the last month $0.70 \%$ (32)

Crack in the last month $0.04 \%$ (2)

Ecstasy in the last month $0.83 \%$ (38)

Tranquilizers in the last month $0.20 \%(9)$

Cannabis in the last month 5.18\% (238)

\footnotetext{
* Highest severity paranoia criterion
} 
https://doi.org/10.1007/s1059

Table 3: Unique effects of job rank, income, class and socioeconomic group on general/occupational health, depressive, paranoia and avoidant symptoms

\begin{tabular}{llll}
\hline Outcome & Predictors & $\begin{array}{l}\text { Standardized } \\
\text { beta }\end{array}$ & $\begin{array}{l}\text { Significance of the } \\
\text { predictor's unique effect }\end{array}$ \\
\hline & & & \\
\hline General health & Job rank & $\beta=-0.04$ & $t=-1.59, p=0.112$ \\
\cline { 2 - 3 } & $\begin{array}{l}\text { Household gross } \\
\text { income }\end{array}$ & $\beta=-0.08$ & $t=-3.77, p=0.001$ \\
\cline { 2 - 4 } & Personal gross income & $\beta=-0.04$ & $t=-1.78, p=0.076$ \\
\hline & $\begin{array}{l}\text { Social class } \\
\text { Socioeconomic group }\end{array}$ & $\beta=-0.03$ & $t=-0.87, p=0.387$ \\
\hline
\end{tabular}

\begin{tabular}{|c|c|c|c|}
\hline \multirow{5}{*}{$\begin{array}{l}\text { Impact of health on } \\
\text { work }\end{array}$} & Job rank & $\beta=0.02$ & $t=0.60, p=0.549$ \\
\hline & $\begin{array}{l}\text { Household gross } \\
\text { income }\end{array}$ & $\beta=0.02$ & $t=1.06, p=0.289$ \\
\hline & Personal gross income & $\beta=0.06$ & $t=2.29, p=0.022$ \\
\hline & Social class & $\beta=0.08$ & $t=2.42, p=0.016$ \\
\hline & Socioeconomic group & $\beta=-0.07$ & $t=-1.77, p=0.077$ \\
\hline \multirow{5}{*}{$\begin{array}{l}\text { Limiting impact of } \\
\text { health on work }\end{array}$} & Job rank & $\beta=0.01$ & $t=0.43, p=0.670$ \\
\hline & $\begin{array}{l}\text { Household gross } \\
\text { income }\end{array}$ & $\beta=0.01$ & $t=0.42, p=0.674$ \\
\hline & Personal gross income & $\beta=0.05$ & $t=1.92, p=0.055$ \\
\hline & Social class & $\beta=0.04$ & $t=1.14, p=0.254$ \\
\hline & Socioeconomic group & $\beta=-0.02$ & $t=-0.56, p=0.575$ \\
\hline
\end{tabular}

Emotional problems $\quad$ Job rank $\quad \beta=0.04 \quad t=1.63, p=0.103$


https://doi.org/10.1007/s1059

\begin{tabular}{|c|c|c|c|}
\hline \multirow[t]{4}{*}{ limiting work } & $\begin{array}{l}\text { Household gross } \\
\text { income }\end{array}$ & $\beta=-0.00$ & $t=-0.12, p=0.905$ \\
\hline & Personal gross income & $\beta=0.05$ & $t=2.24, p=0.025$ \\
\hline & Social class & $\beta=-0.05$ & $t=-1.46, p=0.144$ \\
\hline & Socioeconomic group & $\beta=0.07$ & $t=1.84, p=0.066$ \\
\hline \multirow{5}{*}{$\begin{array}{l}\text { Depressive Symptoms } \\
\text { of the CIS - R }\end{array}$} & Job rank & $\beta=-0.033$ & $t=-1.37, p=0.191$ \\
\hline & $\begin{array}{l}\text { Household gross } \\
\text { income }\end{array}$ & $\beta=-0.019$ & $t=-.878, p=0.380$ \\
\hline & Personal gross income & $\beta=-0.061$ & $t=-2.537, p=0.11$ \\
\hline & Social class & $\beta=-0.070$ & $t=1.857, p=0.43$ \\
\hline & Socioeconomic group & $\beta=-0.124$ & $t=-3.347, p=0.001$ \\
\hline
\end{tabular}

\begin{tabular}{|c|c|c|c|}
\hline $\begin{array}{l}\text { Avoidant Symptoms } \\
\text { of the SCID II }\end{array}$ & Job rank & $\beta=0.026$ & $t=.310, p=0.757$ \\
\hline & $\begin{array}{l}\text { Household gross } \\
\text { income }\end{array}$ & $\beta=-0.195$ & $t=-2.444, p=0.015$ \\
\hline & Personal gross income & $\beta=-0.021$ & $t=.241, p=0.810$ \\
\hline & Social class & $\beta=0.168$ & $t=1.305, p=0.193$ \\
\hline & Socioeconomic group & $\beta=-0.055$ & $t=-0.404, p=0.686$ \\
\hline \multirow{5}{*}{$\begin{array}{l}\text { Paranoia Symptoms of } \\
\text { the PSQ }\end{array}$} & Job rank & $\beta=0.045$ & $t=1.797, p=0.073$ \\
\hline & $\begin{array}{l}\text { Household gross } \\
\text { income }\end{array}$ & $\beta=-0.013$ & $t=-.576, p=0.565$ \\
\hline & Personal gross income & $\beta=0.028$ & $t=1.14, p=0.253$ \\
\hline & Social class & $\beta=-0.040$ & $t=-1.150, p=0.250$ \\
\hline & Socioeconomic group & $\beta=-0.005$ & $t=-.130, p=0.897$ \\
\hline
\end{tabular}


https://doi.org/10.1007/s1059

Psychiatric Disorder

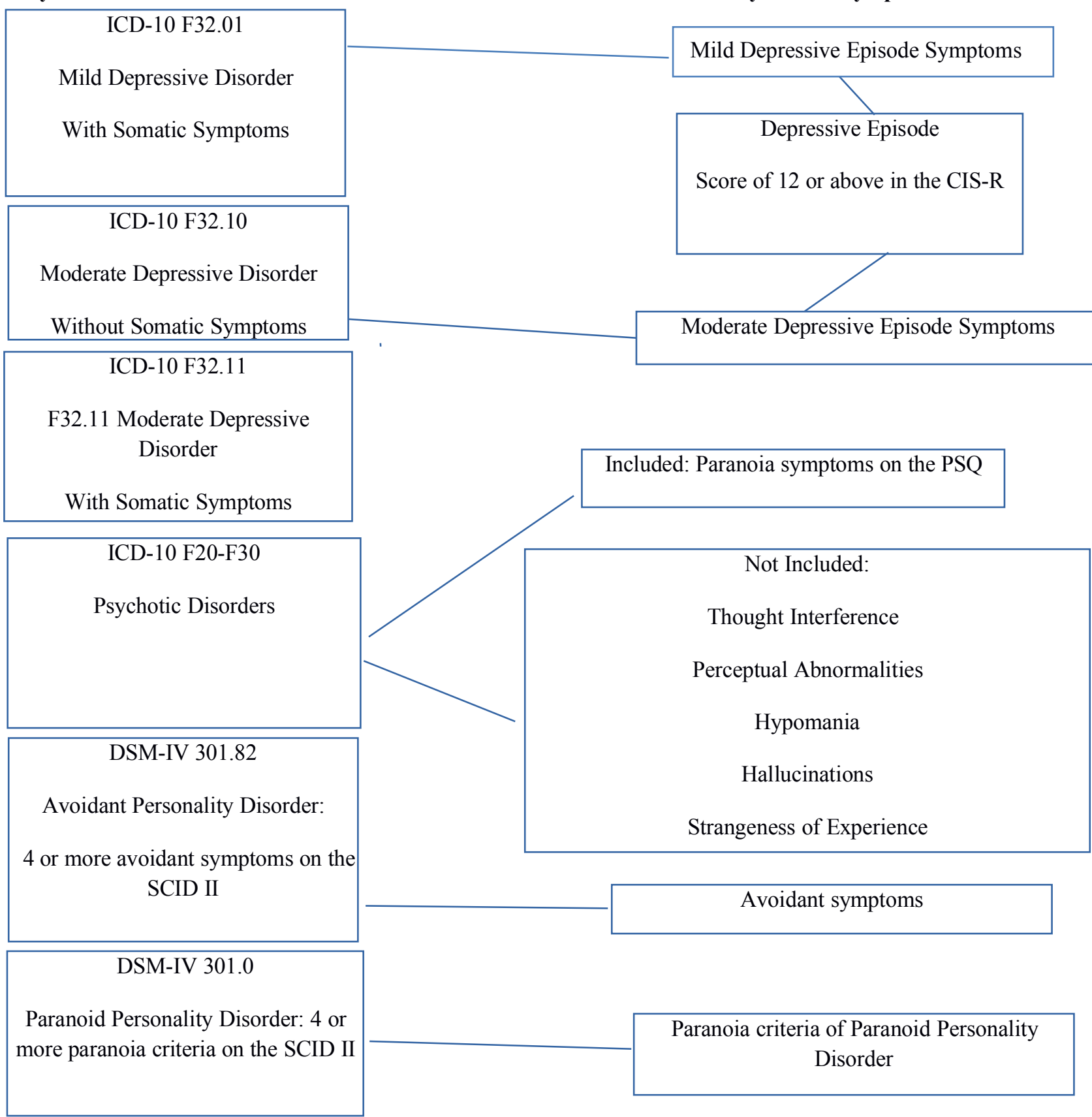

Figure 1. Flowchart to show derivation of disorders in the General National Comorbidity Survey and to illustrate which Psychopathological symptoms are being measured in this sample 
Published in Community Mental Health Journal, 54, 1-14

https://doi.org/10.1007/s1059

\section{Graphs}

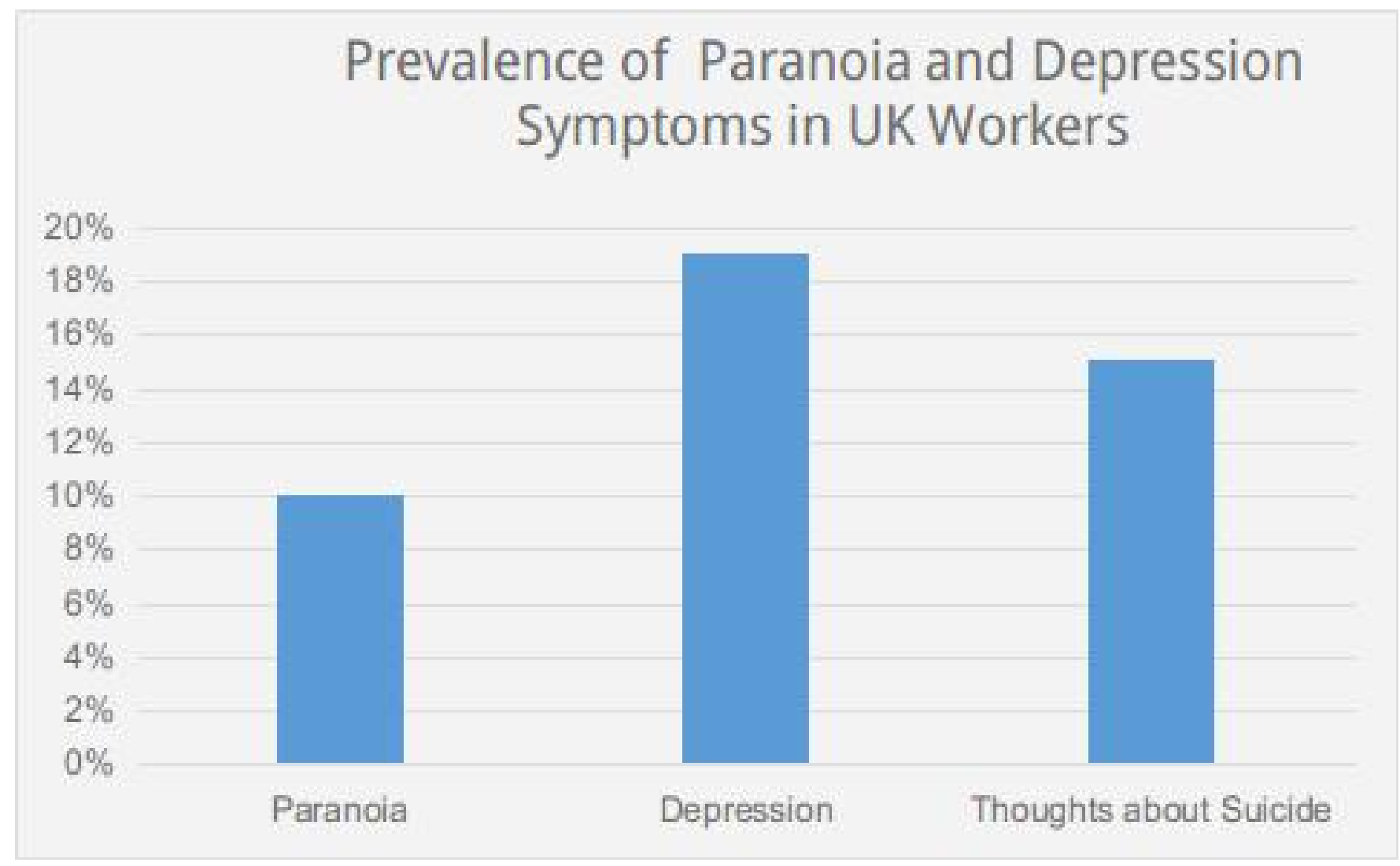


Published in Community Mental Health Journal, 54, 1-14

https://doi.org/10.1007/s1059

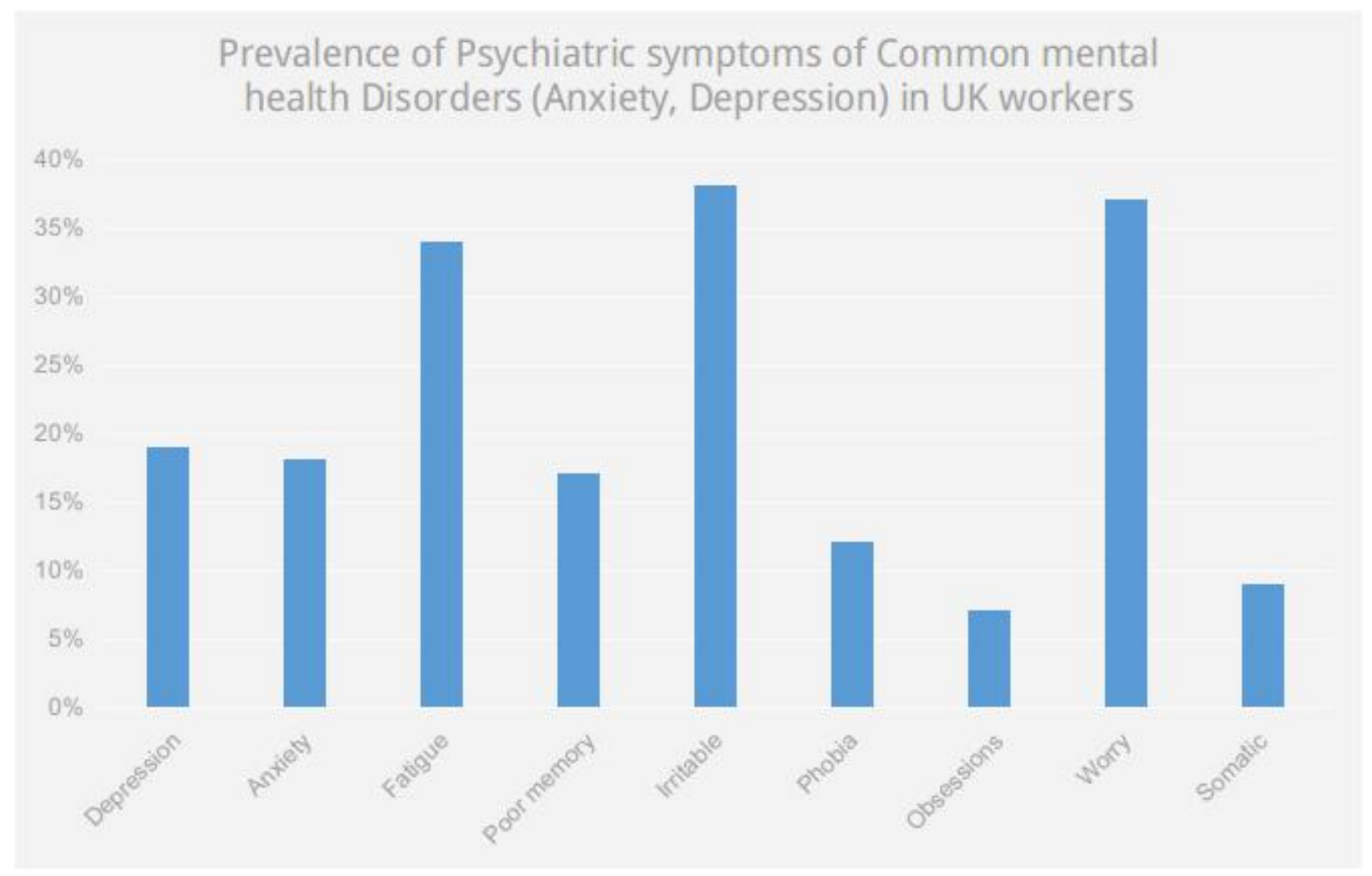


Published in Community Mental Health Journal, 54, 1-14

https://doi.org/10.1007/s1059

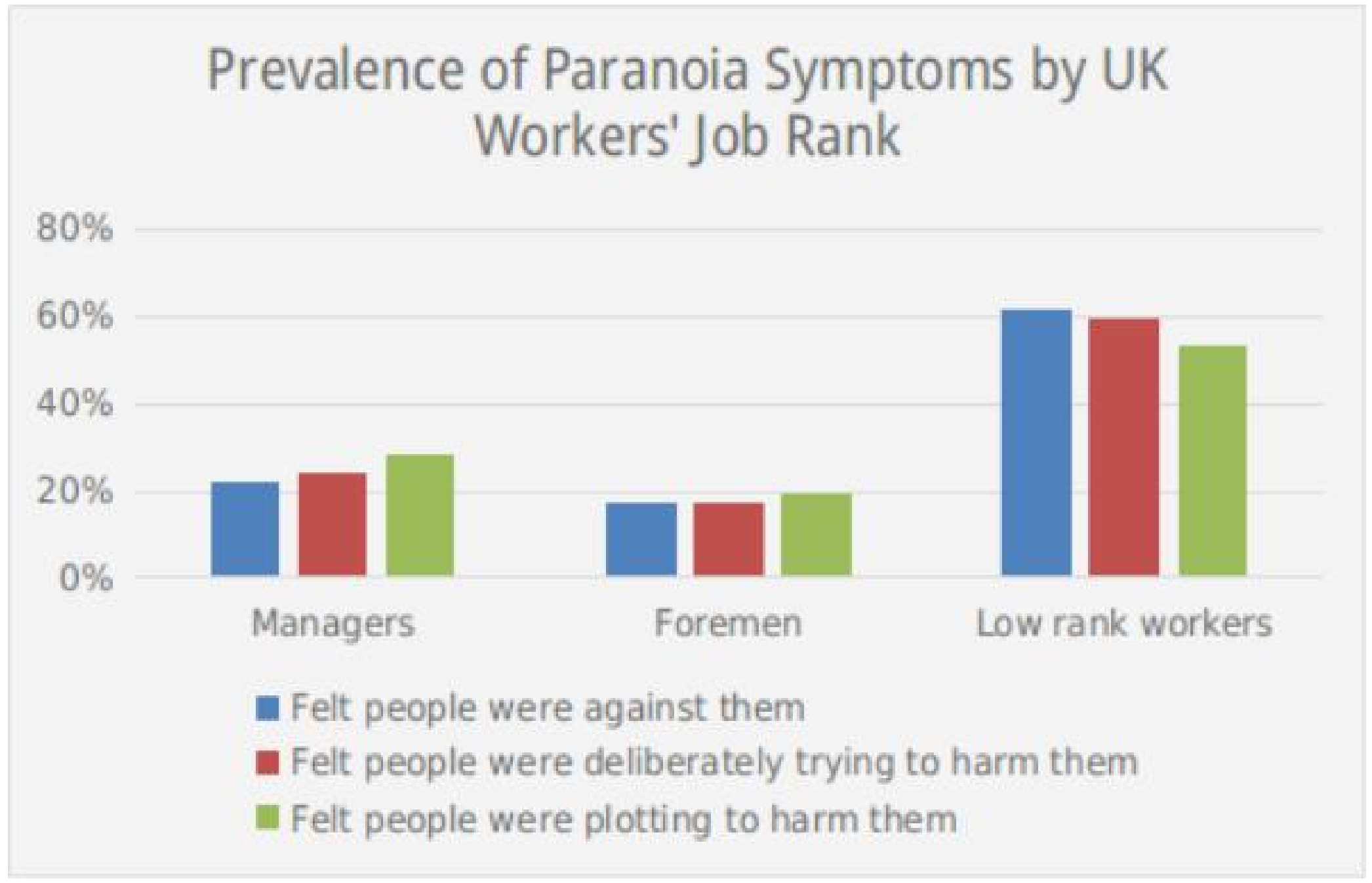


Published in Community Mental Health Journal, 54, 1-14

https://doi.org/10.1007/s1059

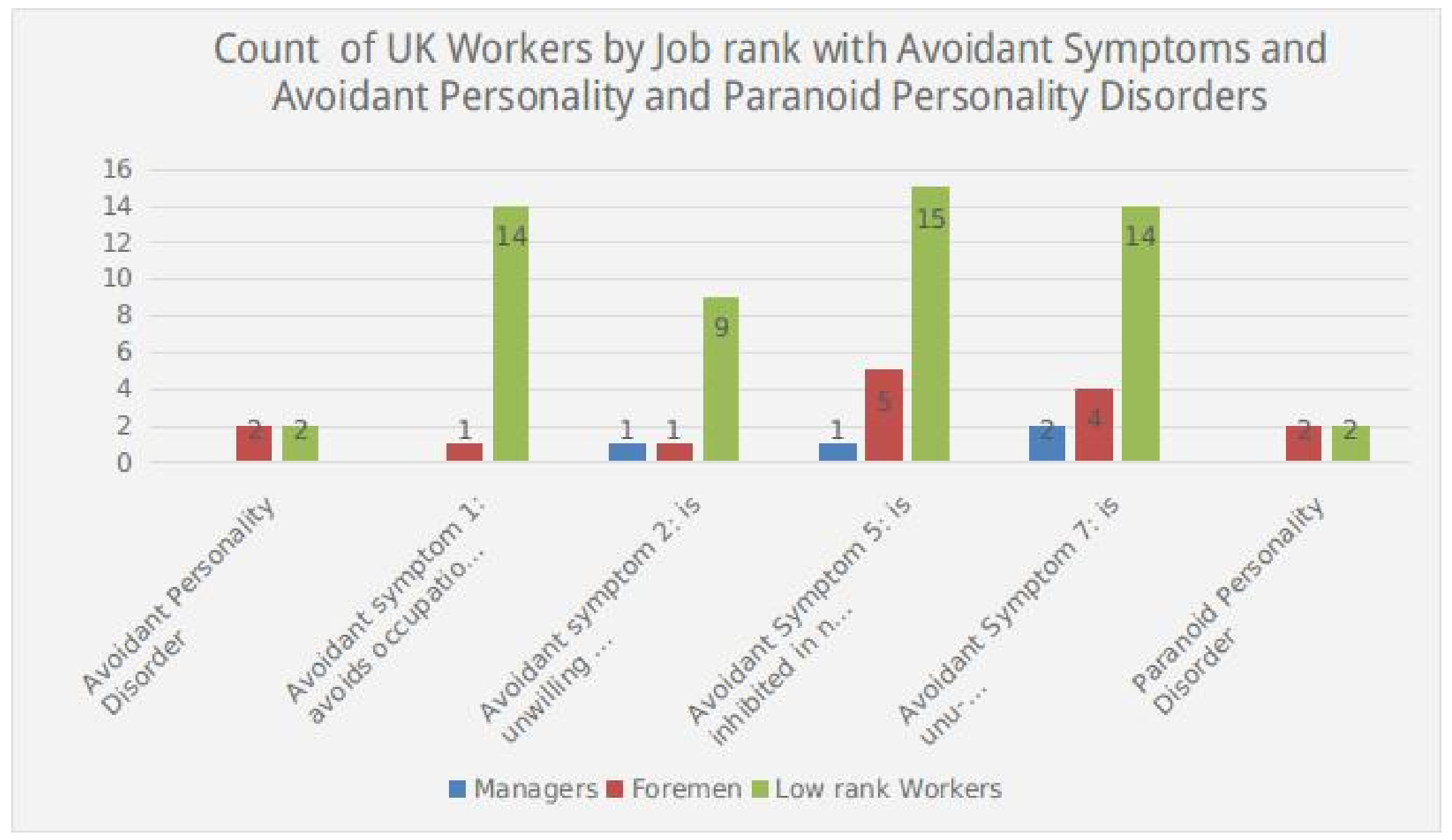


Published in Community Mental Health Journal, 54, 1-14

https://doi.org/10.1007/s1059 